\title{
Study of Convective Flows and Engineering on Residential Buildings
}

\author{
${ }^{1}$ Dmitriy A. Bashmakov, ${ }^{2}$ Aleksey V. Boldyrev, ${ }^{3}$ Gulshat F. Zhuravleva \\ ${ }^{1-3}$ Kazan Federal University \\ Email: bashmakovda@yandex.ru
}

Received: 20 ${ }^{\text {th }}$ August 2019, Accepted: $30^{\text {th }}$ September 2019, Published: $31^{\text {st }}$ October 2019

\begin{abstract}
The paper describes aspects related to the design stages of modern residential buildings. Reflected is the lack of requirements for the presence or absence of stagnant zones in residential premises of apartment buildings. Convective flows were simulated in the living room of a multi-room apartment of a multi-unit standard panel house. It is shown that the presence of stagnant zones along the inner surface of the enclosing structure reduces the energy efficiency of the building.
\end{abstract}

Keywords

A Stagnate Zone, Engineering of Residential Buildings, Living Room, Convective Flow.

\section{Introduction}

Today, they try to make multi-apartment multi-story building projects as individualized as possible, using modern technologies, architectural techniques, and planning decisions. The rejection of the mass use of standard series, which allowed to duplicate standard designs of multi-story buildings, tying them by the nature of the construction site and the peculiarities of the existing architecture, has a positive effect on the appearance of modern housing estates and built-up areas.

Nevertheless, taking into account the economic realities of today, standard projects are widely used to provide the population with so-called economy-class housing, especially when building residential complexes, but much more attention is paid to ensuring the individual appearance of individual buildings and harmonious coordination of buildings of the same type into the original architectural ensemble.

If earlier, by the appearance of the apartment building, it was possible to predict how the apartments are located on the site, how many rooms are in each of them and what planning solutions are used, today it is quite difficult to do this. In this regard, the question arises of preparing a comprehensively justified design of the house, taking into account modern requirements, including and energy-saving requirements.

Modern state standards, joint ventures, SanPins, various decrees, laws, and decrees in force in the Russian Federation affect all stages of building design [8].

The requirements for the minimum class of energy efficiency of apartment buildings are established. Starting from 2016, it is possible to commission buildings with an energy efficiency class of at least B + class, and from 2020 at least B ++ class [1,2]. At the same time, engineering communication systems [3] are a big stumbling block in the design of apartment buildings that satisfy the above requirements.

To meet these requirements, designers use various innovative solutions, both in the field of design and in the use of modern energy-saving materials. However, in modern laws, for example, there are no requirements for stagnant zones in the residential area of an apartment building, therefore, at the design stage, the peculiarities of the airflow in the apartment are not taken into account, but only the thermal engineering analysis of the structures is carried out. This approach to the project does not allow to fully provide a comfortable environment for human habitation, which reduces the life expectancy, and as a consequence, the value of the project $[4,5]$.

\section{Methods}

One of the main functions of the external fence of a building or structure (or the inner wall for separating rooms with different temperatures of the internal air) is the ability of the fence to resist the heat flux passing through it, quantitatively characterized by the heat transfer resistance $\mathrm{R}_{0}, \mathrm{~m}^{2} \cdot{ }^{\circ} \mathrm{C} / \mathrm{W}[7]$.

The method for determining the heat transfer resistance (heat transfer coefficient) of the building envelope is that on the surfaces and in adjacent air environments of the test fence in operating conditions (in a heated building that operates in the cold season), or in a climatic chamber where the temperature The humidity conditions of the indoor and outdoor environments are maintained with the help of special equipment, temperature sensors (for example, thermocouples) are installed, which record during the time values of these thermal characteristics, preferably under stationary conditions of the environments surrounding the fence. The heat transfer resistance of the enclosure is defined as the ratio of the difference of the average temperature of the indoor and outdoor air averaged over the test period to the average density of the heat flux passing through the enclosure.

The reduced heat transfer resistance $\mathrm{R}_{0}$ is determined for building envelopes having heterogeneous sections (heatconducting inclusions, slopes of openings, joints, adjacencies of internal fencing and external fencing, located at an angle to the test site) and the corresponding uneven distribution of temperature and heat fluxes on the surface of the fencing. 
The heat-shielding characteristics of the building envelope are determined during tests in climatic chambers, in which on both sides of the test fragment they create a temperature and humidity regime close to the calculated winter operating conditions, or in natural conditions for the operation of buildings and structures in the winter.

However, only test data for a person's comfortable living is not enough. In this paper, we studied the convective flows for a typical project of the second construction corner bedroom 23 of the 83 section block section near the B-10 axis (Fig. 1).

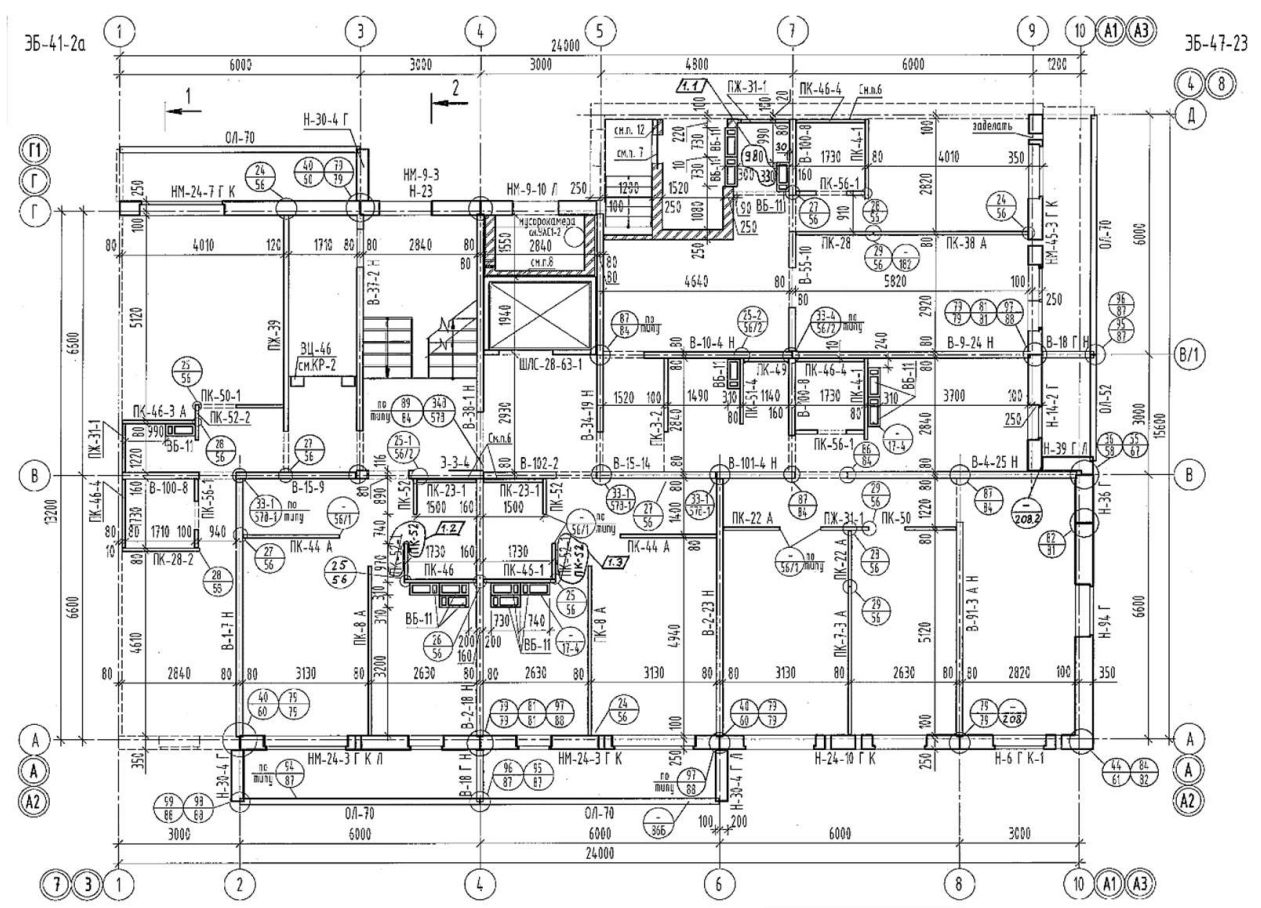

Fig.1: The Scheme of Walls Disposition of 23 Block-Section of 83 Series

This problem was solved in the course of numerical simulation of the movement of internal and external air, as well as heat exchange processes based on the finite volume method using the STAR-CCM + v8.02.011 software package.

\section{Results and Discussions}

For modeling, 3 computational domains were constructed (Fig. 2):

- "Environment" (an area of type "Fluid" for calculating the movement of outdoor air and heat transfer in a certain neighborhood of the building);

- "Walls" (area of type "Solid" for calculating the heat transfer through the walls of the room);

- "Home" (area of type "Fluid" for calculating the movement of indoor air and heat transfer in a room).

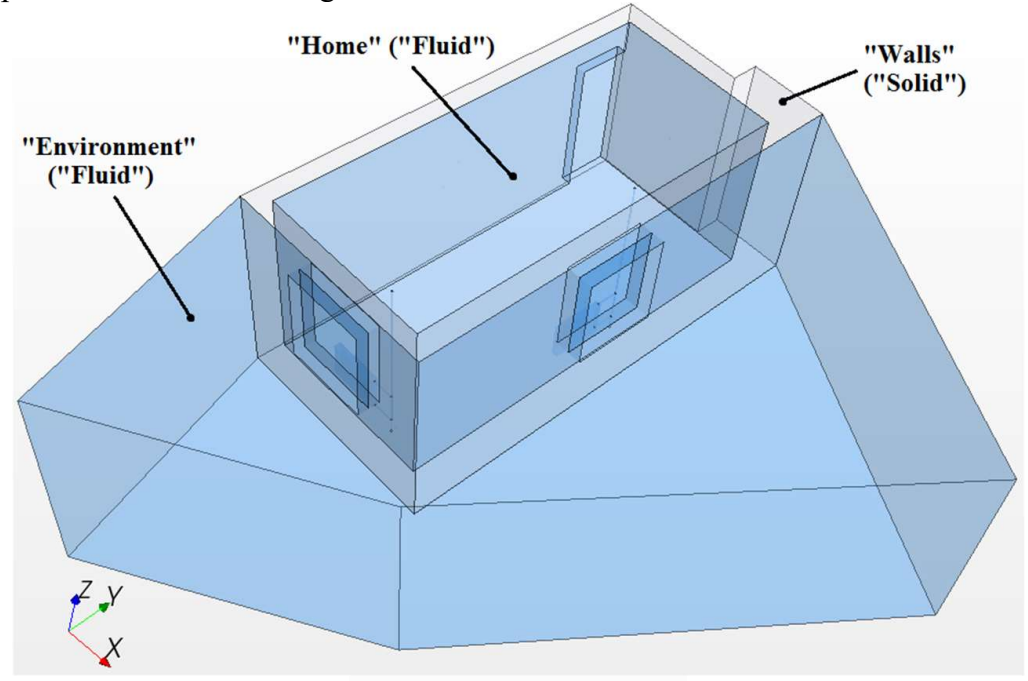

Fig. 2: Calculated Areas 
Since the differential equations of the mathematical model of air movement and heat transfer were solved using numerical methods, the computational domains were previously discretized with the construction of computational grids.

To achieve the necessary accuracy of calculations at a reasonable cost of computing resources, we used mesh from polyhedral cells (type 1) to discretize computational domains, and grids consisting of several layers of prismatic cells of a polygonal shape (type 2) were used near some surfaces.

A type 2 grid is built near solid impermeable surfaces (walls, etc.) and surfaces that are an interface (adjacent surfaces of the above calculation areas). Its parameters were set depending on the sizes of these surfaces and the computational domain, as well as taking into account the features of the calculation of near-wall flows within the framework of the mathematical model used.

The cell size on each surface of the computational domain $\Delta_{c}=\Delta_{\min }=\Delta_{t \text { arg } e t}$ was selected depending on the minimum size of this surface and was refined based on the conditions for achieving grid independence of the solution. As can be seen from Figure 3, the computational grid constructed with the above parameters is rather finely chopped in the "Home" area, especially near the room's windows, as well as near heating appliances and pipelines. The total number of cells is about 2.1 million. For the outer area, a "coarser" computational grid was obtained, which, nevertheless, is sufficient to simulate airflow around the exterior surfaces of the building.

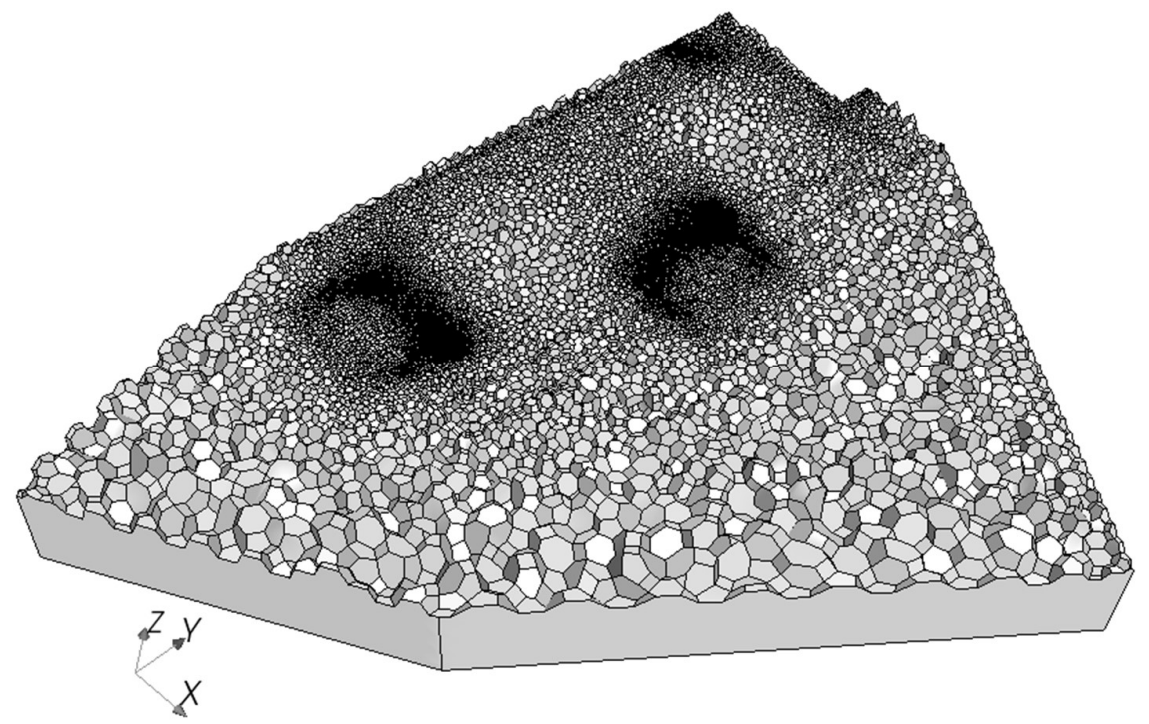

Fig. 3: The Calculated Grid in Some Cut

The mathematical model of the steady-state motion of viscous compressible air and steady-state heat transfer included $[15,16]$ :

1) The law of conservation of matter - a Reynolds-averaged differential equation of continuity;

2) The law of conservation of momentum - the Reynolds-averaged Navier-Stokes differential equations (RANS);

3) The law of conservation of energy - the Reynolds-averaged differential equation of energy;

4) The equation of state of an ideal gas (Clapeyron equation);

5) Differential equations of the two-layer Realizablek- $\varepsilon$ turbulence model for kinetic turbulent energy and its dissipation rate;

6) The Boussinesq hypothesis about the isotropy of turbulence for finding turbulent stresses;

7) Wolfstein model, Jongen mixing function and Reichardt hybrid wall function for speed and temperature (for calculating wall flows and heat transfer).

To simulate natural convection in a room, the mathematical model took into account the compressibility of the gas and the action of one mass force - gravity [14].

It should be noted that when obtaining in the calculations a zero value of kinetic turbulent energy (and, therefore, zero values of turbulent stresses) at some point in the computational domain, the Reynolds equations (RANS) turn into NavierStokes equations. This made it possible to use the mathematical model described above even in those areas of the computational regions where the laminar regime of steady-state air movement was assumed. When simulating heat transfer, the density of the wall material was considered constant.

To simulate the airflow around the exterior surfaces of a building, according to SP 131.133.30-2012 Construction Climatology, at the borders were set $[6,9,10]$ :

- $\quad$ airspeed $0.8 \mathrm{~m} / \mathrm{s}$;

- $\quad$ Air temperature $-32^{\circ} \mathrm{C}$;

- turbulence intensity 0.01 ;

- $\quad$ the linear turbulent scale of $3 \mathrm{~m}$; 
- the direction of air movement.

Moreover, the air was "diverted" from the calculated outer region through the boundaries at which an excess static air pressure of $0 \mathrm{~Pa}$ was determined (at atmospheric pressure $101325 \mathrm{~Pa}$ ), as well as for possible reverse flows at these boundaries:

- $\quad$ Air temperature $-32^{\circ} \mathrm{C}$;

- turbulence intensity 0.01 ;

- the linear turbulent scale of $3 \mathrm{~m}$;

- the direction of air movement is normal to the corresponding boundary.

To ensure air infiltration and heat transfer through the windows of the room on the "porous" interfaces (in accordance with SP 50.133.30-2012 "Thermal protection of buildings"), the following were specified:

- thermal resistance $0.093\left(\mathrm{~m}^{2} \cdot \mathrm{K}\right) / \mathrm{W}$;

- $\quad$ porosity 0.001529 (ratio of the area of cracks to the area of the window);

- coefficient of viscous resistance $14450 \mathrm{~m} / \mathrm{s}$ (to ensure breathability $17 \mathrm{~m}^{3} /\left(\mathrm{m}^{2} \cdot \mathrm{h}\right.$ ) at a pressure drop of 100 $\mathrm{Pa})$;

- $\quad$ inertial resistance coefficient 0 .

For the boundaries reflecting the height (stories number of the house) of the external computational domain, the condition "Plane of symmetry" was established.

For the boundaries, which are solid walls, the conditions of "impermeability" and "non-slip" were set (equality to zero of all projections of the air velocity vector) [12].

To simulate the heat input from heating devices and pipelines of the heating system in the internal calculation area of the house at the borders of the heating radiator, the heat flux density was $q$, B $/ \mathrm{m}^{2}$ (depending on the floor in question and in accordance with the design data). The calculations were carried out for 3 options for the location of the bedroom - 1st floor, middle floor, and 10th floor. Depending on the considered option, the values of thermal parameters were changed at some boundaries of the computational domains [11].

Since air movement and heat transfer were considered as established, when setting the initial conditions for each cell of all the calculation areas, the goal was only to reduce the time required to obtain a convergent solution to the problem [13]. For the approximation of the terms of equations of the mathematical model, implicit second-order schemes are used (for the convective terms of the equations, "counterflow").

The solutions were obtained by the iterative method using the SegregatedFlow algebraic multigrid solver based on the finite volume method, SIMPLE algorithm, and Rhe and Chowd interpolation for the connection of pressure and speed on computational grids with nodes combined for different variables.

In each calculation, the convergence of the solution was controlled by the level of normalized root-mean-square residuals for all differential equations of the mathematical model, as well as by the stabilization of some local and integral characteristics (for example, heat flux densities through the walls of the room $q, \mathrm{BT} / \mathrm{m}^{2}$, air temperature at a point located approximately in the center of the bedroom $\mathrm{T}^{*},{ }^{\circ} \mathrm{C}$, etc.).

By integrating the calculated vector field of the air velocity, streamlines were obtained that make it convenient to judge the parameters and location of convective flows in the room (Fig. 4)

It is noteworthy that directly in the corner zone, near the marked zones A and B in Figure 3, either no airflow is observed at all, or its speed is close to zero, i.e. a stagnant zone is formed (especially wide near the floor and ceiling of the room).

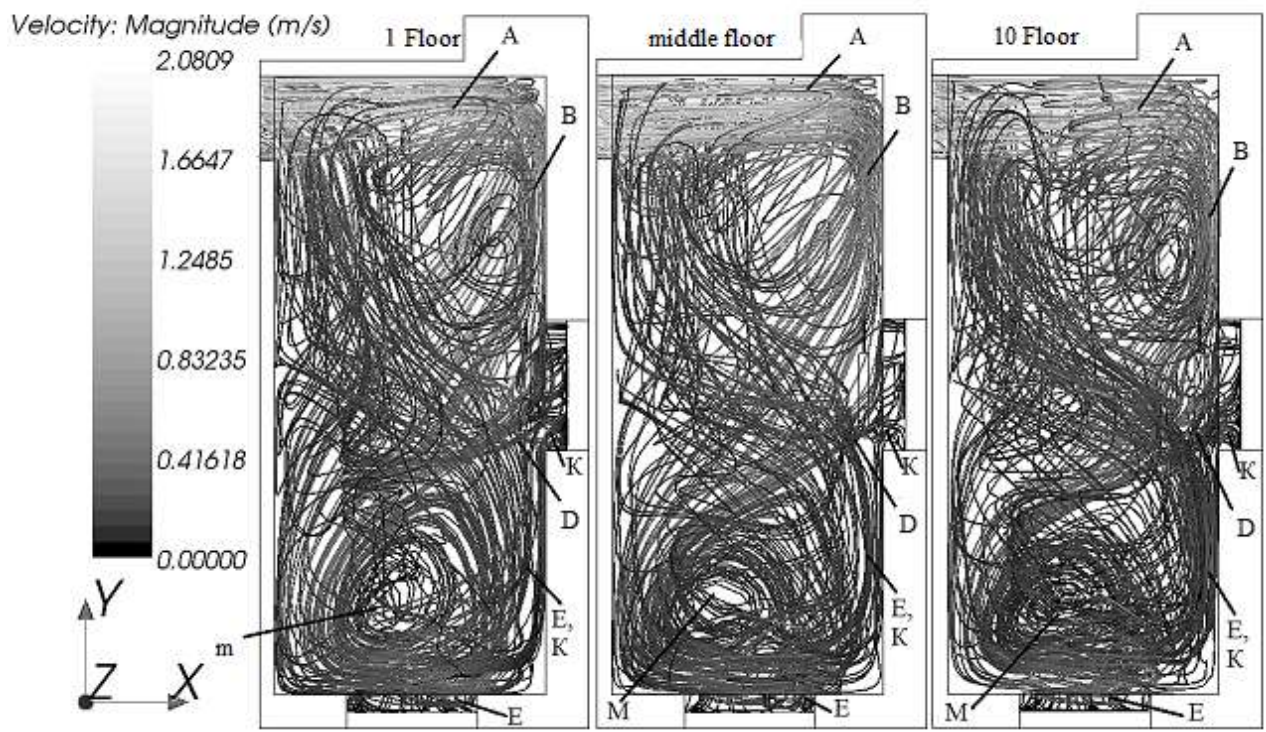

Fig. 4: Streamline in the Room for the $1^{\text {st }}$, Middle, $10^{\text {th }}$ Floors (Top Plan View) 
As follows from the temperature distribution on the walls for the 1st, middle (Figure 5) and 10th floors, in the indicated stagnant region, the wall temperature is noticeably lower than the optimum $<(20 . .22)^{\circ} \mathrm{C}$. In addition, extensive zones of low wall temperature (up to $(7 . .8)^{\circ} \mathrm{C}$ ) were found in its lower part (closer to the window).The area of these zones increases with an increase in the number of stories of the room in question.

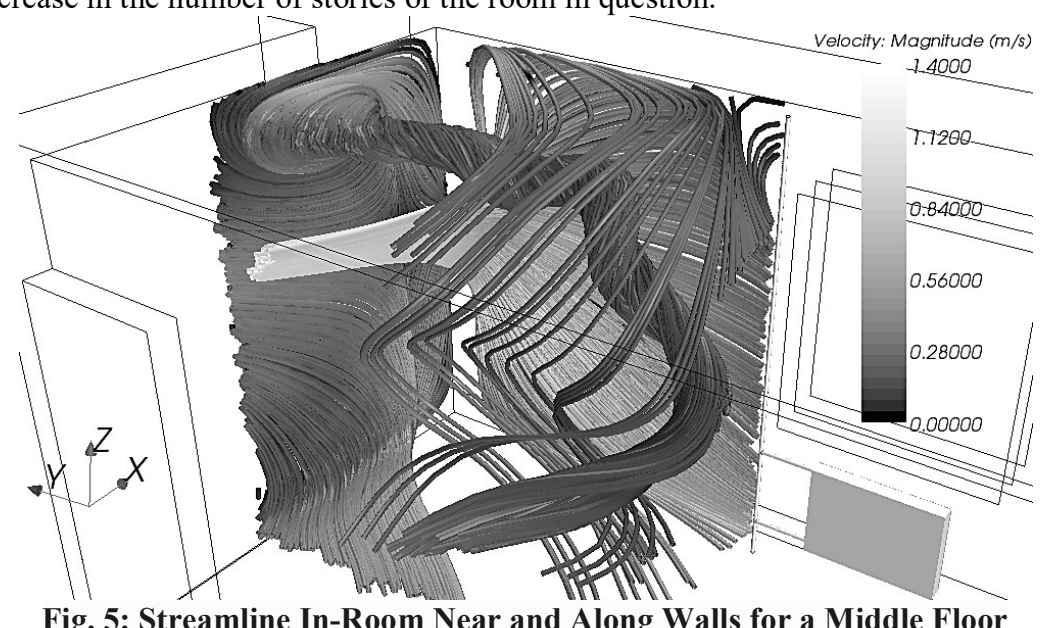

\section{Summary}

Fig. 5: Streamline In-Room Near and Along Walls for a Middle Floor

As a result of the work carried out, the presence of a stagnant zone (a zone without airflow around it) was determined for a small part of the internal surface of a structural element of a living room adjacent to the B-10 assembly (Fig. 1, 4) over the entire height of the room and a width of $30 \mathrm{~cm}$ (counting from the corner). The presence of this zone leads to a local increase in air humidity in the above-described location of the second construction corner bedroom 23 of the block section of the 83 series. Taking into account the detected lower limit values of the temperature of the above angle, mold will form in it, with an increase in the humidity of the structure, heat losses will increase.

In connection with the foregoing, we can conclude that it is necessary to simulate convective flows at the design stage of an apartment building, which will allow you to correctly locate utilities, in particular, heating appliances. This approach will improve the quality of life of future residents and increase energy efficiency at home without additional capital investments.

\section{Acknowledgments}

The work is performed according to the Russian Government Program of Competitive Growth of Kazan Federal University.

\section{References}

[1] Designer reference. Internal sanitary facilities. Part 1: Heating / Ed. I.G. Staroverova and Yu.I. Schiller. - M .: Stroyizdat, 1990.- 344 pages.

[2] Order of the Ministry of Regional Development of the Russian Federation of 04/08/ 2011 No. 161 "On approval of the Rules for determining the energy efficiency classes of apartment buildings and the requirements for the energy efficiency class indicator of an apartment building located on the facade of an apartment building"

[3] Order of the Ministry of Regional Development of the Russian Federation of 05/28/2011 No. 262 "On the requirements of energy efficiency of buildings, structures, structures"

[4] A.A. Balashov. Design of heating systems and ventilation of civil buildings: a training manual / A.A. Balashov, N.Yu. Polunina. - Tambov: Publishing House of FSBEI HPE "TSTU", 2011. - 88 pages.

[5] GOST 30494-96<x id="3"/><x id="4"/> Residential and public buildings. Indoor microclimate parameters.

[6] SanPiN 2.1.2.2645-10 Sanitary-epidemiological requirements for accommodation in residential buildings and premises.

[7] 13330.2012 "Thermal protection of buildings"; Revised edition of SNiP 23-02-2003

[8] O. Turan, R.J. Poole, N. Chakraborty, Influences of boundary conditions on laminar natural convection in rectangular enclosures with differentially heated side walls, (2012) International Journal of Heat and Fluid Flow, 33 (1), pp. 131-146.

[9] L. Namli, Effects of the built-in balcony on thermal performance in residential buildings: A case study, 2016, Journal of Building Physics 40 (2), pp. 125-143

[10] N.C. Markatos, K.A. Pericleous. Laminar and turbulent natural convection in an enclosed cavity, (1984) International Journal of Heat and Mass Transfer, 27 (5), pp. 755-772.

[11] SP 131.13330.2012 Construction climatology. The updated edition of SNiP 23-01-99* 
[12] J.M. Gorman, E.M. Sparrow, Katz, S.D.M., W.J. Minkowycz. Convective heat transfer coefficients on all external surfaces of a generic residential building in crossflow, Numerical Heat Transfer; Part A: Applications Volume 75, Issue 2, Pages 71-90

[13] D.L. Loveday, A.H. Taki. Convective heat transfer coefficients at a plane surface on a full-scale building facade, (1996) International Journal of Heat and Mass Transfer, 39 (8), pp. 1729-1742.

[14] M.G. Emmel, M.O. Abadie, N. Mendes. New external convective heat transfer coefficient correlations for isolated low-rise buildings, (2007) Energy and Buildings, 39 (3), pp. 335-342.

[15] P.A. Fokaides, S.A. Kalogirou. Application of infrared thermography for the determination of the overall heat transfer coefficient (U-Value) in building envelopes, (2011) Applied Energy, 88 (12), pp. 4358-4365

[16] T.H. Mehedi, R.B. Tahzeeb, Islam, A.K.M.S., Numerical analysis of steady and transient natural convection in an enclosed cavity, 2017, AIP Conference Proceedings 1851.020097 